\title{
Bronchoscopic lung volume reduction by endobronchial valve in advanced emphysema: the first Asian report
}

This article was published in the following Dove Press journal:

International Journal of COPD

29 July 2015

Number of times this article has been viewed

\author{
Tai Sun Park' \\ Yoonki Hong ${ }^{2}$ \\ Jae Seung Lee' \\ Sang Young $\mathrm{Oh}^{3}$ \\ Sang Min $\mathrm{Lee}^{3}$ \\ Namkug Kim ${ }^{3}$ \\ Joon Beom Seo ${ }^{3}$ \\ Yeon-Mok Oh' \\ Sang-Do Lee' \\ Sei Won Lee' \\ 'Department of Pulmonary and \\ Critical Care Medicine and Clinical \\ Research Center for Chronic \\ Obstructive Airway Diseases, Asan \\ Medical Center, University of Ulsan \\ College of Medicine, Seoul, Korea; \\ ${ }^{2}$ Department of Internal Medicine, \\ College of Medicine, Kangwon \\ National University, Chuncheon, \\ Korea; ${ }^{3}$ Department of Radiology \\ and Research Institute of Radiology, \\ Asan Medical Center, University \\ of Ulsan College of Medicine, \\ Seoul, Korea
}

Purpose: Endobronchial valve (EBV) therapy is increasingly being seen as a therapeutic option for advanced emphysema, but its clinical utility in Asian populations, who may have different phenotypes to other ethnic populations, has not been assessed.

Patients and methods: This prospective open-label single-arm clinical trial examined the clinical efficacy and the safety of EBV in 43 consecutive patients (mean age $68.4 \pm 7.5$, forced expiratory volume in 1 second $\left[\mathrm{FEV}_{1}\right] 24.5 \% \pm 10.7 \%$ predicted, residual volume $208.7 \% \pm 47.9 \%$ predicted) with severe emphysema with complete fissure and no collateral ventilation in a tertiary referral hospital in Korea.

Results: Compared to baseline, the patients exhibited significant improvements 6 months after EBV therapy in terms of $\mathrm{FEV}_{1}$ (from $0.68 \pm 0.26 \mathrm{~L}$ to $0.92 \pm 0.40 \mathrm{~L} ; P<0.001$ ), 6-minute walk distance (from $233.5 \pm 114.8 \mathrm{~m}$ to $299.6 \pm 87.5 \mathrm{~m} ; P=0.012$ ), modified Medical Research Council dyspnea scale (from $3.7 \pm 0.6$ to $2.4 \pm 1.2 ; P<0.001$ ), and St George's Respiratory Questionnaire (from $65.59 \pm 13.07$ to $53.76 \pm 11.40 ; P=0.028)$. Nine patients $(20.9 \%$ ) had a tuberculosis scar, but these scars did not affect target lobe volume reduction or pneumothorax frequency. Thirteen patients had adverse events, ten (23.3\%) developed pneumothorax, which included one death due to tension pneumothorax.

Conclusion: EBV therapy was as effective and safe in Korean patients as it has been shown to be in Western countries. (Trial registration: ClinicalTrials.gov: NCT01869205).

Keywords: bronchoscopy, chronic obstructive pulmonary disease, collateral ventilation, fissure integrity, treatment outcome

\section{Introduction}

Chronic obstructive pulmonary disease (COPD) is a leading cause of disability and death worldwide. ${ }^{1}$ It is characterized by chronic airflow limitation that is caused by a mixture of small airway disease and parenchymal destruction. ${ }^{2}$ Lung parenchyma destruction, also known as emphysema, results in decreased elastic recoil, progressive hyperinflation, and air trapping, which in turn lead to dyspnea and decreased lung function. Currently, bronchodilator is the mainstay of COPD treatment, and it can improve dyspnea and lung function. However, these treatments are less effective in emphysema-dominant phenotype. ${ }^{3}$

Lung volume reduction surgery (LVRS) entails resection of lung areas that are particularly hyperinflated. It was developed as a palliative treatment for severe emphysema ${ }^{4,5}$ and clearly improves lung function, exercise capacity, and survival in appropriately selected patients. ${ }^{6}$ However, it also associated with substantial procedure-related morbidity and mortality. Therefore, less invasive bronchoscopic
Department of Pulmonary and Critical Care Medicine and Clinical Research Center for Chronic Obstructive Airway Diseases, Asan Medical Center, University of Ulsan College of Medicine 88 Olympic-ro 43-gil, Songpa-gu,

Seoul, Korea

Tel +82230103990

Fax +82230106968

Email iseiwon@gmail.com 
approaches for treating hyperinflation in advanced emphysema have been proposed. Several bronchoscopic lung volume reduction (BLVR) methods have shown the similar physiological effects of LVRS with lower morbidity and mortality. $^{7}$

However, the efficacies of BLVR have been documented mostly in the studies of Western countries. It is unclear whether these effects are still consistent in Asian population because the COPD phenotypes of Asian and Western patients may differ. ${ }^{8-10}$ Along with tobacco smoking, previous exposure to biomass fuels or dust-bearing jobs, and treated pulmonary tuberculosis (TB) are also major causes of COPD in Asia. ${ }^{11,12}$ The prevalence of TB is relatively higher in the Asia-Pacific area, ${ }^{13}$ and it is significant because the history of TB is associated with airway and parenchymal scarring causing airflow limitation, a characteristics of COPD. ${ }^{11,14,15}$

The COPD heterogeneity indicates that the feasibility of BLVR in this population should be assessed. We previously reported the results of a small pilot study on the short-term feasibility and safety of BLVR with endobronchial valve (EBV) in the Koreans. ${ }^{16}$ However, the long-term efficacy and safety of EBV treatment of severe emphysema in Asia have not been assessed. This study is an extension of the previous pilot study. Its aim was to prospectively assess the clinical efficacy and safety of BLVR with EBV in Asians with different medical environment and distinct clinical phenotype from those of Westerns.

\section{Materials and methods Study design and patients}

This is a prospective open-label single-arm clinical trial. Its main objective was to evaluate the effectiveness of BLVR with EBVs in patients with severe emphysema who had "complete target lobar exclusion". ${ }^{17}$ The primary outcome measurements were mean changes in pulmonary function, exercise capacity, and quality of life after the procedure. The secondary outcomes included clinical response predictors and procedure-related complications.

Patients with advanced emphysema who did not respond sufficiently to the standard treatment for COPD were considered to be eligible. In July 2012-December 2013, consecutive patients were recruited from the pulmonary clinic at Asan Medical Center, Seoul, Korea. Written informed consent was obtained from each patient. The study received approval from The Institutional Review Board of Asan Medical Center.

Patient selection criteria were based on previous studies. ${ }^{18-20}$ Patient inclusion criteria were an age of $\geq 40$ years, a smoking history of $>10$ pack year, the presence of advanced heterogeneous emphysema on chest computed tomography (CT), a forced expiratory volume in 1 second $\left(\mathrm{FEV}_{1}\right)$ of $\leq 45 \%$ of predicted value, a total lung capacity (TLC) of $>100 \%$ of predicted value, a residual volume (RV) of $>150 \%$ of predicted value, persistent dyspnea despite optimal medical treatment and pulmonary rehabilitation for more than 3 months, and negative collateral ventilation of the target lobe. Patients with homogeneous or incomplete fissure of the target lobe on CT, collateral ventilation of the target lobe, a diffusing capacity for carbon monoxide corrected by alveolar ventilation $\left(\mathrm{DL}_{\mathrm{CO}} / \mathrm{V}_{\mathrm{A}}\right)$ of $<20 \%$ of predicted value, giant bullae $(>5 \mathrm{~cm})$ at the ipsilateral lobe, previous thoracotomy, excessive sputum, severe pulmonary hypertension, an active respiratory infection, and/or an unstable cardiac condition were excluded.

\section{BLVR procedure}

BLVR was performed with a flexible bronchoscope (BF-1T60 ${ }^{\circledR}$ or BF-1T $260^{\circledR}$, Olympus, Tokyo, Japan) by placing Zephyr ${ }^{\circledR}$ EBVs (Pulmonx, Inc., Redwood City, CA, USA) in the bronchi of the target lobe. Patients were given intravenous anesthesia using midazolam $(0.05-0.08 \mathrm{mg} / \mathrm{kg})$ under spontaneous ventilation. Before placing the EBVs, the Chartis ${ }^{\mathrm{TM}}$ system (Pulmonx, Inc.) was used to confirm that the target lobe lacked collateral ventilation with other lobes. ${ }^{19}$ Collateral ventilation was deemed to be absent when the air flow declined gradually over time after occlusion of the target lobe airway with a balloon catheter. However, if persistent airflow was observed after occlusion for more than 5 minutes, significant collateral ventilation was suspected. ${ }^{21}$ After the procedure, daily chest X-ray was performed until 5 days after the procedure to ensure the EBVs were adequately placed and to detect possible atelectasis or pneumothorax. Chest CT was performed before the procedure by using a dual-source CT system (SOMATOM Definition; Siemens Healthcare, Forchiheim, Germany). Fissure integrity was assessed by experienced thoracic radiologists who were unaware of the clinical information. The fissure was defined as "complete" when it could separate two adjacent lobes in more than $90 \%$ on at least one plane (axial and coronal planes) on thin-slice CT. ${ }^{20}$ Heterogeneity was screened by lobar emphysema and heterogeneity scoring, which was used in the previous study. ${ }^{18}$ The extent of emphysema was graded on a lobar level on a scale of $0-4$ (called emphysema score). Heterogeneity was defined as $\geq 2$ of heterogeneity score, which was derived by subtracting the best emphysema score for the worst emphysema score in single lung. Additionally, heterogeneity was assessed by 
the ratio of perfusion and volume of each lobe per whole lung after lobe segmentation. The perfusion-to-volume ratio of each lobe was calculated by quantitatively measuring the increased CT density caused by iodine in each voxel of each lobe using the in-house software. ${ }^{22,23}$ The target lobe was selected on the basis of these CT data (ie, the most hyperinflated and the least perfused lobe) after discussions between a pulmonologist and two radiologists (Figure 1).

\section{Assessment of outcomes}

Baseline evaluations were performed before the procedure. These included detailed history taking, physical examination, chest radiography, $\mathrm{CT}$, laboratory examination, pulmonary function tests, and the 6-minute walk distance (6MWD). Health-related quality of life was documented by using the modified Medical Research Council (mMRC) dyspnea scale and St George's Respiratory Questionnaire (SGRQ).

Three and six months after the procedure, clinical effectiveness was assessed by measuring $\mathrm{FEV}_{1}, 6 \mathrm{MWD}, \mathrm{mMRC}$, and SGRQ. Target lobe volume reduction (TLVR) was defined as $>50 \%$ volume reduction of the target lobe on chest $\mathrm{X}$-ray at 3 months and was measured on the basis of visual assessments of the two thoracic radiologists.

Adverse events were recorded, including death, pneumothorax, pneumonia, empyema, hemoptysis, and acute COPD exacerbations.

\section{Statistical analysis}

All descriptive continuous variables were presented as the mean \pm SD. For all study variables, the follow-up data were compared to the baseline data by using paired $t$-test (the Wilcoxon signed rank test). Minimum clinically important differences (MCID) for outcome variables were used as recommended, ${ }^{24}$ and they were $\geq 100 \mathrm{~mL}^{\text {for }} \mathrm{FEV}_{1},{ }^{25} \geq 26 \mathrm{~m}$ for $6 \mathrm{MWD},{ }^{26}$ and $\geq 4$ units for SGRQ. ${ }^{27}$ Groups were compared by using Pearson's chi-squared test or MannWhitney $U$-test. For key variables, the study data were compared to the data of previous trials by using Student's $t$-test. $P$-values $<0.05$ were considered to indicate statistical
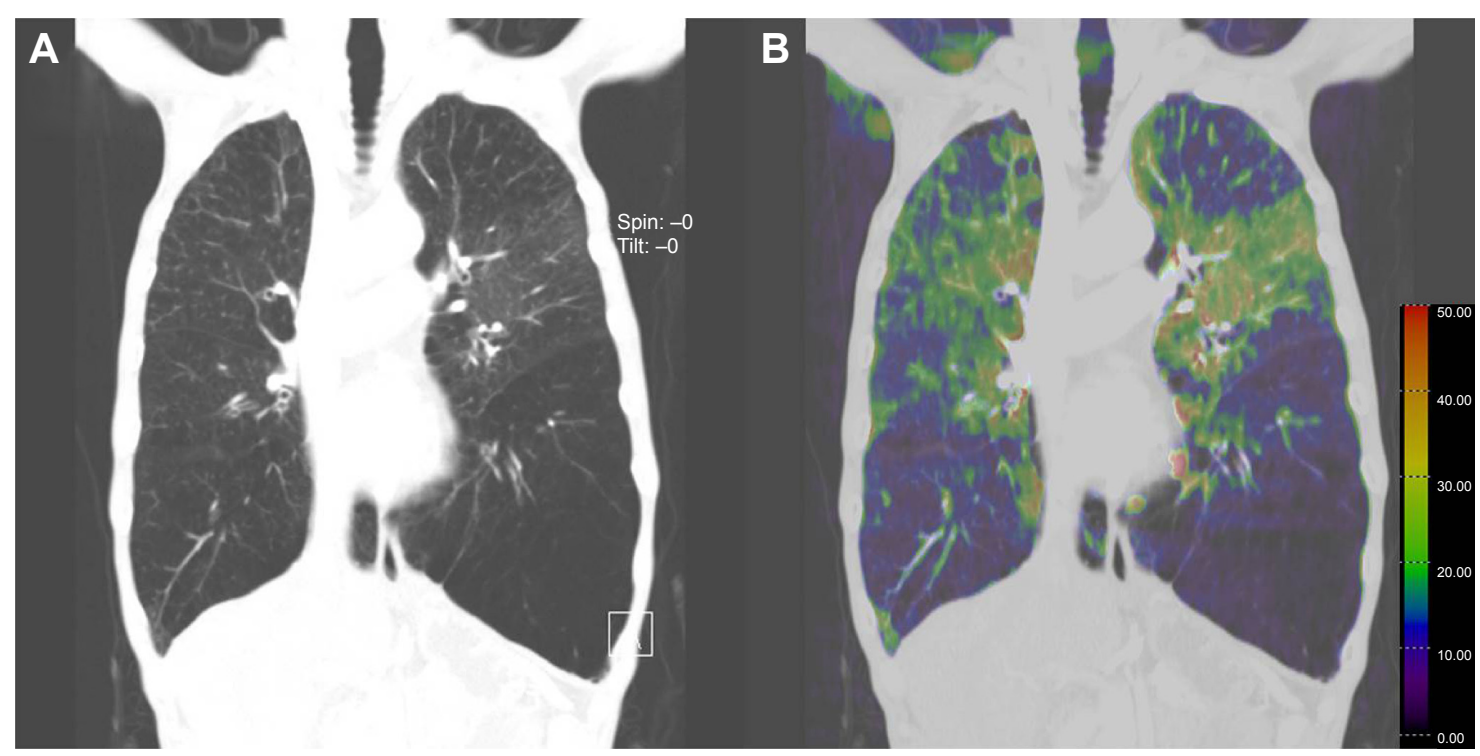

\begin{tabular}{|lll|}
\hline Lobe & Perfusion per whole lung & Volume per whole lung \\
\hline Right upper lobe & 0.22 & 0.16 \\
Right middle lobe & 0.07 & 0.07 \\
Right lower lobe & 0.30 & 0.26 \\
Left upper lobe & 0.21 & 0.18 \\
Left lower lobe & $\mathbf{0 . 2 0}$ & $\mathbf{0 . 3 3}$ \\
\hline Total & 1.00 & 1.00 \\
\hline
\end{tabular}

Figure I An example of target lobe selection on the basis of dual-source computed tomography.

Notes: (A) Lung setting image. (B) Quantitative perfusion image. The perfusion is presented from red (normal) to black (no perfusion). (C) Quantitative analysis of perfusion and volume for each lobe. In this patient, the left lower lobe was selected as target lobe (as shown by the bold) since it had the lowest fraction of perfusion compared with its volume (0.20/0.33). It means that left lower lobe is the most emphysematous and hyperinflated. 
significance; all $P$-values were two tailed. Statistical analysis was performed by using SPSS 21.0 software for Windows (SPSS, Chicago, IL, USA).

\section{Results}

\section{Patients}

In total, 83 consecutive patients were screened during the study period for inclusion in the study. Six patients were excluded because of collateral ventilation of target lobe on Chartis $^{\mathrm{TM}}$ system, although they had complete fissure of target lobe on CT scan. The remaining 43 patients underwent BLVR with EBVs. Their baseline characteristics are shown in Table 1. Of these patients, 35 and 27 were followed up for 3 months and 6 months, respectively (Figure 2).

\section{Procedural details}

The right upper lobe was most frequently targeted for treatment $(n=18,41.9 \%)$, followed by the left lower $(n=15,34.9 \%)$, right lower $(n=6,14.0 \%)$, and left upper

Table I Baseline characteristics of the patients

\begin{tabular}{|c|c|}
\hline Variables & $\mathbf{N}=43$ \\
\hline \multicolumn{2}{|l|}{ Demographic characteristics } \\
\hline Age, years & $68.4 \pm 7.5$ \\
\hline Sex, male & $40(93 \%)$ \\
\hline Body mass index, $\mathrm{kg} / \mathrm{m}^{2}$ & $18.5 \pm 3.1$ \\
\hline \multicolumn{2}{|l|}{ Smoking, pack years } \\
\hline Has ever smoked & $43(100 \%)$ \\
\hline Number of pack years & $45.1 \pm 15.8$ \\
\hline Receiving long-term oxygen therapy & 17 (39.5\%) \\
\hline History of pulmonary tuberculosis & $10(23.3 \%)$ \\
\hline \multicolumn{2}{|l|}{ Pulmonary function } \\
\hline $\mathrm{FEV}_{1}, \mathrm{~L}$ & $0.68 \pm 0.26$ \\
\hline $\mathrm{FEV}_{1}, \%$ predicted & $24.5 \pm 10.7$ \\
\hline FVC, L & $2.50 \pm 0.75$ \\
\hline FVC, \%predicted & $63.8 \pm 17.3$ \\
\hline TLC, L & $7.5 I \pm 1.20$ \\
\hline TLC, \%predicted & $126.7 \pm 18.8$ \\
\hline $\mathrm{RV}, \mathrm{L}$ & $4.98 \pm 1.15$ \\
\hline RV, \%predicted & $208.7 \pm 47.9$ \\
\hline $\mathrm{DL}_{\mathrm{co}}, \mathrm{mL} / \mathrm{min} / \mathrm{mmHg}$ & $6.1 \pm 2.5$ \\
\hline $\mathrm{DL}_{\mathrm{co}}, \%$ predicted & $31.6 \pm 11.9$ \\
\hline $\mathrm{DL}_{\mathrm{co}} / \mathrm{VA}, \%$ predicted & $51.02 \pm 17.8$ \\
\hline \multicolumn{2}{|l|}{ Functional assessment } \\
\hline 6MWD, m & $233.5 \pm 1 \mid 4.8$ \\
\hline \multicolumn{2}{|l|}{ Quality of life and dyspnea } \\
\hline SGRQ total score & $65.59 \pm 13.07$ \\
\hline mMRC dyspnea scale & $3.7 \pm 0.6$ \\
\hline
\end{tabular}

Note: The data are presented as mean \pm SD or $\mathrm{n}(\%)$ unless otherwise stated. Abbreviations: $\mathrm{DL}_{\mathrm{co}}$, diffusing capacity for carbon monoxide; $\mathrm{FEV}_{1}$, forced expiratory volume in I second; FVC, forced vital capacity; mMRC, modified Medical Research Council; RV, residual volume; SGRQ, St George's Respiratory Questionnaire; TLC, total lung capacity; VA, alveolar volume; 6MWD, 6-min walk distance test; SD, standard deviation. $(\mathrm{n}=1,2.3 \%)$ lobes. Both the right upper and middle lobes were selected as the target lobes in six patients $(14.0 \%)$ because of collateral ventilation between those lobes. The median number of EBVs inserted per patient was three (range: 2-5). A TB scar was present in the target lobe of five patients $(11.6 \%)$ or in the adjacent lobe of five patients (11.6\%). TLVR after the procedure was achieved in 36 of the 43 patients $(83.7 \%)$. The mean hospital days of patients without and with pneumothorax were $7.4 \pm 3.2$ and $14.7 \pm 13.2$, respectively.

\section{Efficacy outcomes}

In the patients who were followed up at 3 months and 6 months, the $\mathrm{FEV}_{1}$ increased from $0.68 \pm 0.26 \mathrm{~L}$ to $0.89 \pm 0.37 \mathrm{~L}$ and $0.92 \pm 0.40 \mathrm{~L}$, respectively (both $P<0.001$ ), the 6MWD improved from $233.5 \pm 114.8 \mathrm{~m}$ to $283.7 \pm 121.6 \mathrm{~m}$ $(P=0.001)$ and $299.6 \pm 87.5 \mathrm{~m}(P=0.012)$, respectively, the dyspnea scale (mMRC) dropped from $3.7 \pm 0.6$ to $2.5 \pm 1.2$ and $2.4 \pm 1.2$ (both $P<0.001$ ), respectively, and the SGRQ total scores fell from $65.59 \pm 13.07$ to $55.70 \pm 13.79(P=0.019)$ and 53.76 $\pm 11.40(P=0.028)$, respectively (Figure 3$)$. Of the patients who were followed up at 3 months and 6 months, the $\mathrm{FEV}_{1}$ MCID ( $\left.\geq 100 \mathrm{~mL}\right)$ was achieved by $27 / 35(77.1 \%)$ and 17/27 (63.0\%), respectively, the 6MWD MCID (26 m) was achieved by $19 / 30(63.3 \%)$ and $15 / 21(71.4 \%)$, and the SGRQ MCID (total score $\leq 4$ points) was achieved by $17 / 27$ (63.0\%) and 15/20 (75.0\%), respectively (Figure 4). RV was decreased from $208.7 \pm 47.9 \mathrm{~L}$ to $165.0 \% \pm 47.7 \%$ predicted at 3 months and $155.9 \% \pm 42.6 \%$ predicted at 6 months (both $P<0.001)$. Other pulmonary function test data are shown in Table S1.

Although all 43 patients had complete exclusion of target lobe (as confirmed by CT scan and the Chartis ${ }^{\mathrm{TM}}$ system), TLVR was not achieved in seven patients (16.3\%). Compared to patients without TLVR, the patients with TLVR had significantly greater improvements in $\mathrm{FEV}_{1}$ relative to baseline at both $3(0.26 \pm 0.22 \mathrm{~L}$ vs $-0.02 \pm 0.17 \mathrm{~L}, P=0.001)$ and 6 months $(0.29 \pm 0.23 \mathrm{~L}$ vs $-0.02 \pm 0.13 \mathrm{~L}, P=0.002)$. Similarly, the patients with TLVR tended to have greater improvements in 6MWD and SGRQ total score at 3 months and 6 months, although these differences did not achieve statistical significance (Table 2).

Regarding the ten patients $(23.3 \%)$ with a history of previously treated pulmonary $\mathrm{TB}$, nine patients had TB scars in the target or adjacent lobe, as determined by CT. The patients with and without a TB scar did not differ significantly in terms of TLVR achievement or development of pneumotho$\operatorname{rax}$ (Table S2). 


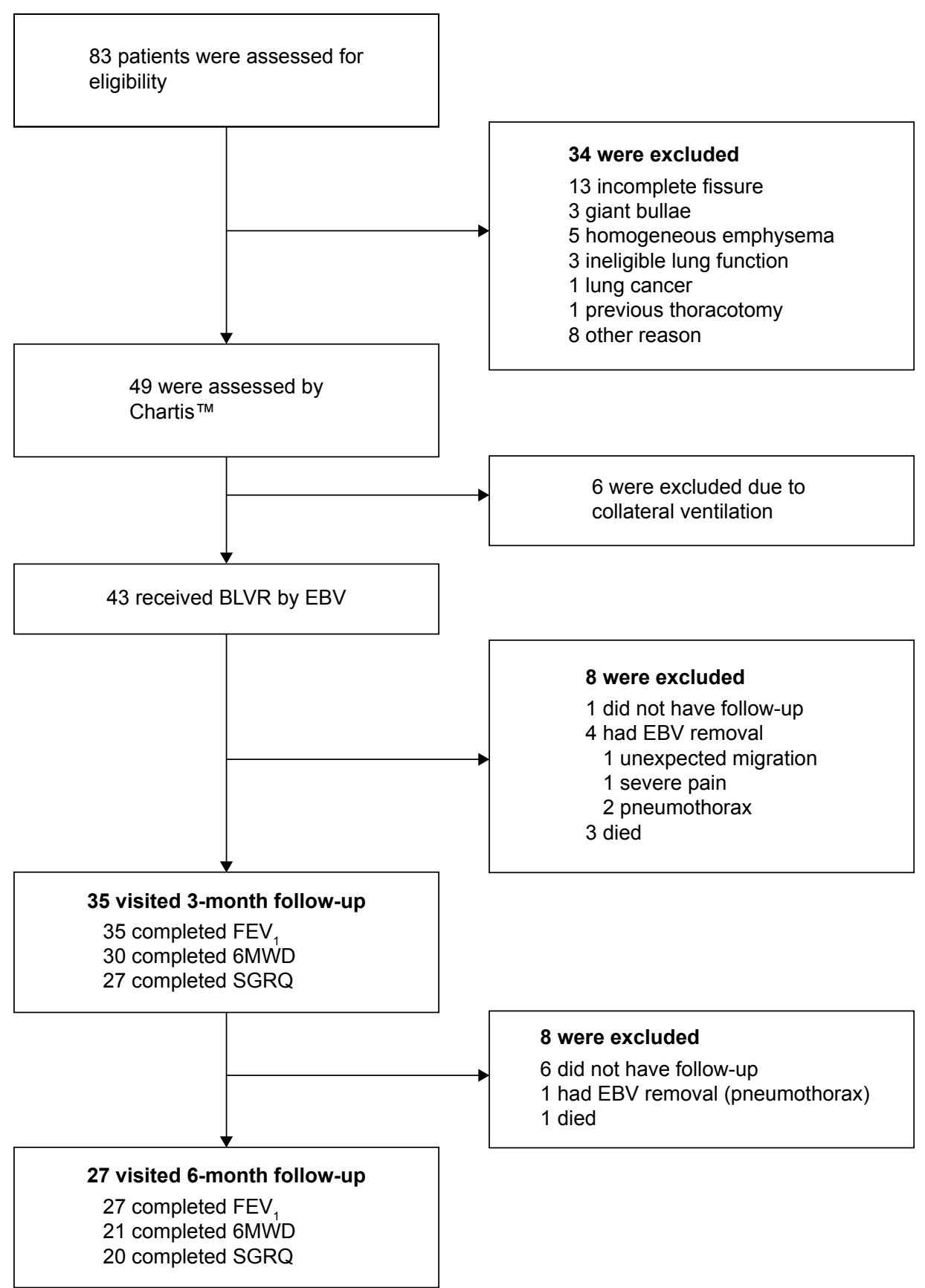

Figure 2 Flow chart indicating patient disposition in the study.

Abbreviations: BLVR, bronchoscopic lung volume reduction; EBV, endobronchial valve; FEV, forced expiratory volume in I second; SGRQ, St George's Respiratory Questionnaire; 6MWD, 6-minute walk distance test.

\section{Safety outcomes}

All follow-up patients were monitored for adverse events. Thirteen of the 43 patients (30.2\%) developed complications. Four patients died within 6 months of the procedure. In the one procedure-related mortality case, tension pneumothorax developed 2 days after BLVR and the patient expired due to sudden-onset ventricular fibrillation. The other three patients did not exhibit clinical effectiveness after BLVR and died of chronic respiratory failure. Ten of the 43 patients (23.3\%) developed pneumothorax. The median time to pneumothorax onset after BLVR was two (range: 1-26) days. Eight of the ten pneumothorax cases required chest tube insertion. Four patients exhibited prolonged air leakage ( $\geq 7$ days). Some or all inserted EBVs were removed from three of these four patients for lung expansion (Table 3). Two patients whose pneumothorax was successfully treated with a chest tube developed a recurrence of pneumothorax. Of the ten patients who developed pneumothorax after BLVR, six and four were 
A

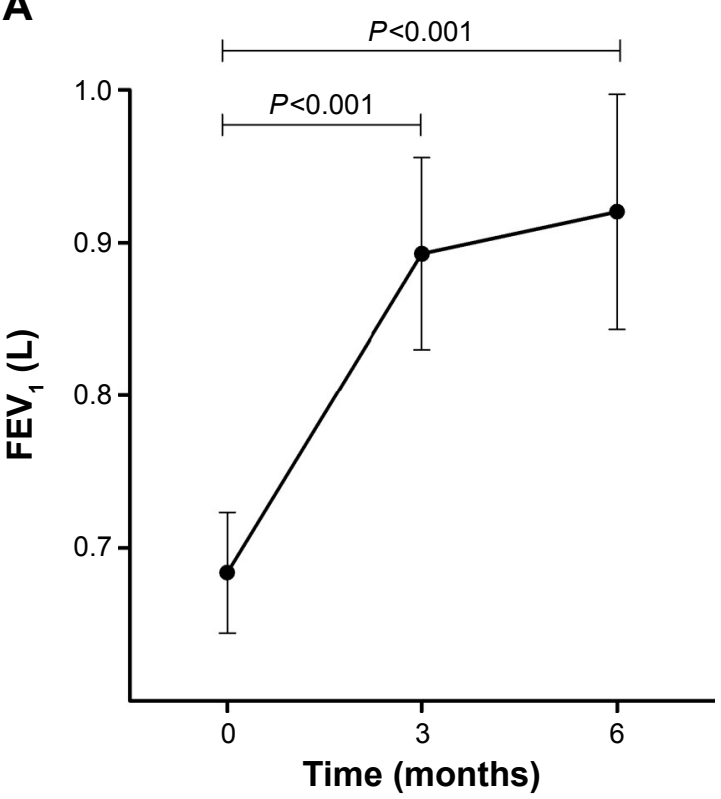

C

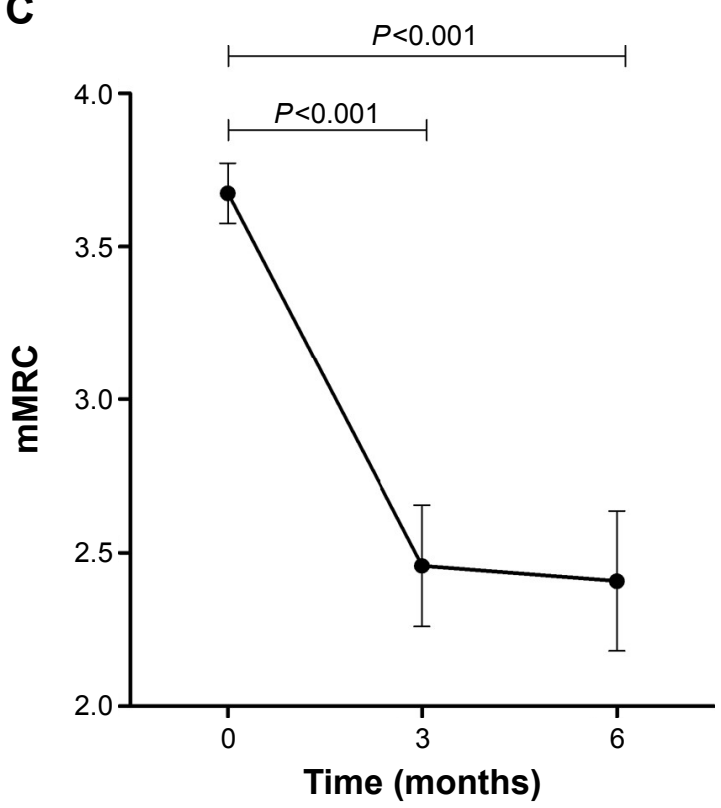

B

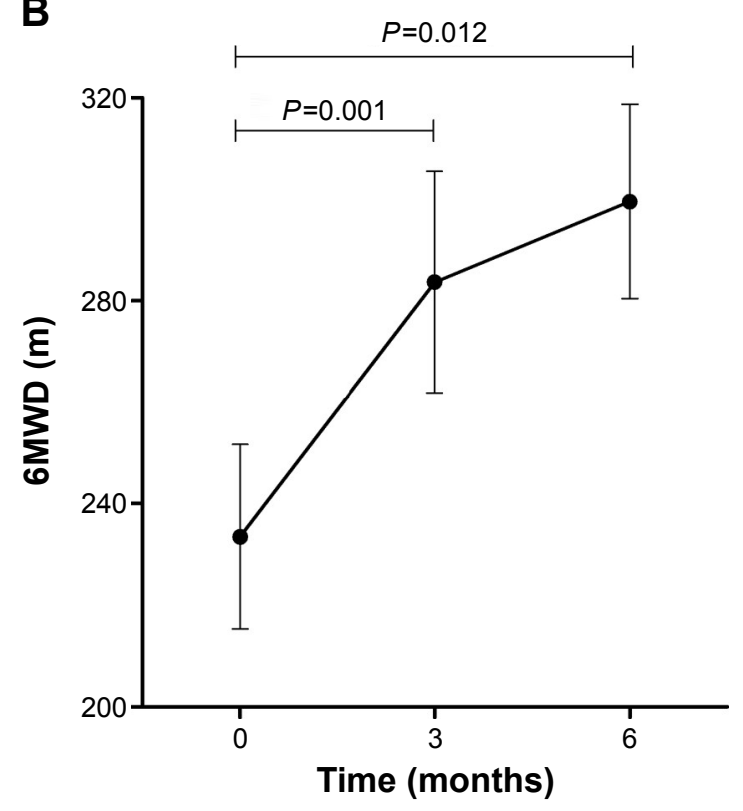

D

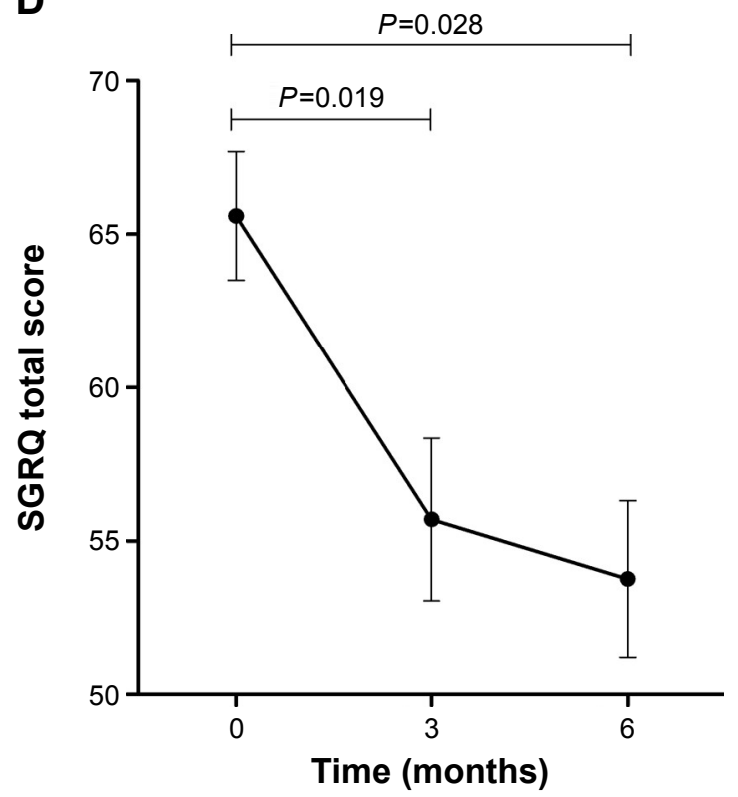

Figure 3 Primary outcomes 3 and 6 months after endobronchial valve therapy relative to baseline.

Abbreviations: $\mathrm{FEV}_{1}$, forced expiratory volume in I second; 6MWD, 6-minute walk distance test; mMrc, modified Medical Research Council dyspnea scale; SGRQ, St George's Respiratory Questionnaire.

followed up at 3 months and 6 months, respectively. The $\mathrm{FEV}_{1}$ MCID (>100 mL) was achieved by four $(66.7 \%)$ and three (75\%) of these patients, respectively. Three studies have examined the outcomes of BLVR with EBVs in Western countries, namely, the USA VENT study (NCT00129584), ${ }^{28}$ the European VENT study (NCT00129584), ${ }^{20}$ and the Chartis ${ }^{\mathrm{TM}}$ study (NCT01101958). ${ }^{19}$ The incidence of pneumothorax was significantly higher in our study than in these three studies $(23.3 \%$ vs $10.6 \%, P=0.03) .{ }^{29}$ Comparison of baseline characteristics indicated that the patients in our study were older and had a lower body mass index (BMI) and a poorer exercise capacity than those in the preceding studies. Moreover, although the baseline $\mathrm{FEV}_{1}$ in our cohort was lower, our patients also had less hyperinflation (as measured by RV) (Table 4).

\section{Discussion}

In the past decade, BLVR has become recognized as a therapeutic option for advanced emphysema. However, its 


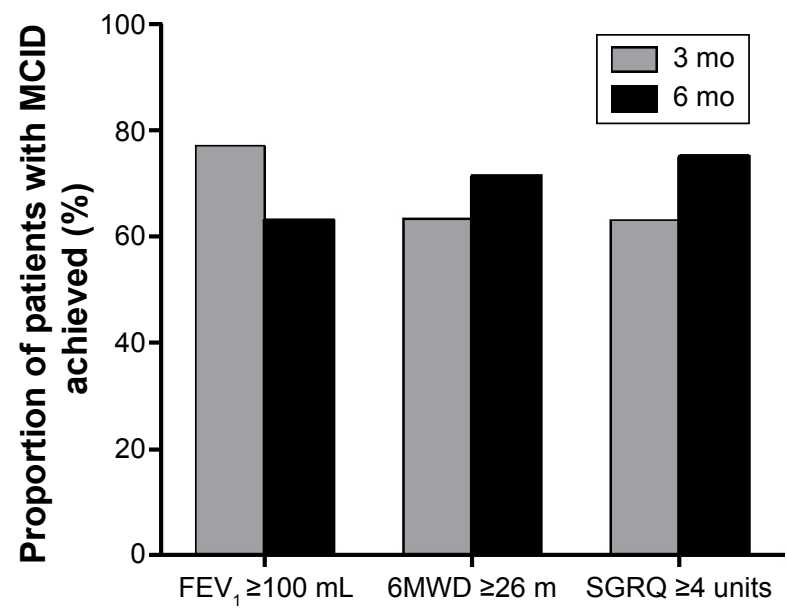

Figure 4 Proportion of patients whose clinical outcomes after endobronchial valve therapy exceed the minimum clinically important differences $F E V_{1}, 6 M W D$ and SGRQ. Abbreviations: $\mathrm{FEV}_{1}$, forced expiratory volume in I second; 6MWD, 6-minute walk distance; SGRQ, St George's Respiratory Questionnaire.

clinical utility in Asian populations has not been assessed yet. Our study investigated the relatively long-term outcomes of BLVR with EBV in Koreans with severe emphysema and found that BLVR with EBV is effective and acceptably safe in this population, and there were significant improvements in $\mathrm{FEV}_{1}, 6 \mathrm{MWD}$, and SGRQ that were sustained for 6 months. These observations are comparable with those of other studies. ${ }^{19,20,28,30}$

In our cohort, BLVR yielded definite clinical effects in terms of primary outcomes at 3 months, including FEV, (absolute change $0.21 \pm 0.24 \mathrm{~L}$, percent change $33.1 \% \pm 33.2 \%$ ), SGRQ (difference $-6.7 \pm 10.5$ ), and 6MWD (absolute change $55.1 \pm 92.3 \mathrm{~m}$, percent change $54.4 \% \pm 120.5 \%$ ). The improvements in these variables at 3 months were higher than the improvements detected by previous studies. ${ }^{19,20}$ The outcomes at 6 months were similar to the 3 months

Table 2 Primary outcomes relative to baseline in patients who did and did not achieve target lobe volume reduction

\begin{tabular}{|c|c|c|c|}
\hline & \multicolumn{2}{|c|}{$\begin{array}{l}\text { Target lobe volume } \\
\text { reduction }\end{array}$} & \multirow[t]{2}{*}{$P_{\text {-value }}$} \\
\hline & Yes $(n=28)$ & No $(n=7)$ & \\
\hline \multicolumn{4}{|l|}{3 months } \\
\hline$\Delta \mathrm{FEV}_{1}(\mathrm{~L})$ & $0.26 \pm 0.22$ & $-0.02 \pm 0.17$ & 0.001 \\
\hline$\triangle 6 M W D(m)$ & $64.2 \pm 84.6$ & $-4.0 \pm 131.5$ & 0.298 \\
\hline$\Delta S G R Q$ total (score) & $-7.0 \pm 11.3$ & $-5.2 \pm 6.7$ & 0.606 \\
\hline \multicolumn{4}{|l|}{6 months } \\
\hline$\Delta \mathrm{FEV}_{\mathrm{I}}(\mathrm{L})$ & $0.29 \pm 0.23$ & $-0.02 \pm 0.13$ & 0.002 \\
\hline$\triangle 6 M W D(m)$ & $68.2 \pm 102.0$ & $-4.8 \pm 46.4$ & 0.065 \\
\hline$\triangle S G R Q$ total (score) & $-8.1 \pm 16.5$ & $-7 . I \pm 6.2$ & 0.516 \\
\hline
\end{tabular}

Notes: The data are presented as mean \pm SD. ${ }^{a}$ The two groups were compared by using the Mann-Whitney $U$-test.

Abbreviations: FEV , forced expiratory volume in I second; SGRQ, St George's Respiratory Questionnaire; 6MWD, 6-minute walk distance test; SD, standard deviation.
Table 3 Adverse events in the 6 months after bronchoscopic lung volume reduction with endobronchial valve. $(n=43)$

\begin{tabular}{ll}
\hline Events & $\mathbf{n}$ \\
\hline Death, all causes & $4(9.3 \%)$ \\
Related to procedure & $\mathrm{I}(2.3 \%)$ \\
Unrelated to procedure & $3(7.0 \%)$ \\
Pneumothorax & $10(23.3 \%)$ \\
Oxygen supply only & $2(4.7 \%)$ \\
Chest tube $<7$ days & $3(7.0 \%)$ \\
Prolonged air leak $\geq 7$ days & $4(9.3 \%)$ \\
Requiring surgical intervention & $2(4.7 \%)$ \\
Postobstructive pneumonia & $\mathrm{I}(2.3 \%)$ \\
Pneumonia in other than target lobe & $0(0 \%)$ \\
Empyema & $0(0 \%)$ \\
Hemoptysis & $4(9.3 \%)$ \\
Nonmassive & $4(9.3 \%)$ \\
Massive & $0(0 \%)$ \\
Valve migration & $\mathrm{I}(2.3 \%)$ \\
Intractable pain & $\mathrm{I}(2.3 \%)$ \\
Acute exacerbation of COPD & $0(0 \%)$ \\
\hline
\end{tabular}

Note: The data are presented as $n(\%)$.

outcomes ( $\mathrm{FEV}_{1}$ absolute change: $0.22 \pm 0.25 \mathrm{~L}$, percent change: $32.4 \% \pm 34.2 \%$; SGRQ difference points: $-8.0 \pm 15.7$; 6MWD absolute change: $54.3 \pm 97.5 \mathrm{~m}$, percent change: $49.7 \% \pm 107.5 \%)$. The greater improvements in our study relative to those in other studies could reflect the judicious selection of the patients, which was based on the results of the previous clinical trials. In particular, of the eligible patients with heterogeneous emphysema with complete fissure on $\mathrm{CT}$, patients were only selected for BLVR if the Chartis ${ }^{\mathrm{TM}}$ system confirmed that there was no collateral ventilation. Moreover, the target lobe was carefully selected on the basis

Table 4 Comparison of our study results with those of previous trials in Western countries in terms of pneumothorax frequency and baseline characteristics

\begin{tabular}{|c|c|c|c|}
\hline & This study & $\begin{array}{l}\text { Previous } \\
\text { trials }^{\mathbf{a}}\end{array}$ & $P$-value \\
\hline \multicolumn{4}{|l|}{ Pneumothorax } \\
\hline $\begin{array}{l}\text { Incidence in complete } \\
\text { fissure patients, (\%) }\end{array}$ & $23.3 \%$ & $10.6 \%$ & 0.03 \\
\hline $\begin{array}{l}\text { Median time to onset, } \\
\text { days (range) }\end{array}$ & $2(I-26)$ & $2(0-272)$ & \\
\hline \multicolumn{4}{|c|}{ Baseline characteristics, mean (SE) } \\
\hline Age, years & $68.4(1.14)$ & $62.8(1.70)$ & $<0.001$ \\
\hline Body mass index, $\mathrm{kg} / \mathrm{m}^{2}$ & $18.5(0.47)$ & $23.9(0.61)$ & $<0.001$ \\
\hline $\mathrm{FEV}_{1}$, \%predicted & $24.5(1.63)$ & $30.0(0.53)$ & 0.001 \\
\hline RV, \%predicted & $208.7(7.3 \mathrm{I})$ & $232.0(8.07)$ & 0.002 \\
\hline 6MWD & $233.5(17.53)$ & $333.9(4.77)$ & $<0.001$ \\
\hline
\end{tabular}

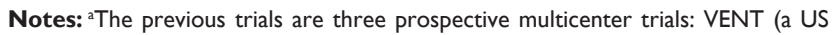
study cohort [NCTO0 29584] and a European cohort [NCTO0I29584]) and the multicenter Chartis ${ }^{\mathrm{TM}}$ trial (NCTOI I01958).

Abbreviations: $\mathrm{FEV}_{\text {, }}$, forced expiratory volume in I second; RV, residual volume; $\mathrm{SE}$, standard error; 6MWD, 6-minute walk distance test. 
of quantitative CT analysis that indicated the degree of perfusion and hyperinflation of the lobes.

It is important to ensure that there is no collateral ventilation between the target lobe and other lobes because it promotes the achievement of TLVR, which is an important predictor of clinical improvement after BLVR. ${ }^{31}$ Two methods, namely, CT and the Chartis ${ }^{\mathrm{TM}}$ system have been used to predict the presence of collateral ventilation. ${ }^{32} \mathrm{CT}$ can detect collateral ventilation with high sensitivity, but its specificity (44\%) is low. ${ }^{33}$ This has been clearly demonstrated by post hoc analyses of the previous trials: TLVR (volume reduction of target lobe $>50 \%$ ) was achieved in only $32.5 \%$ of patients with complete fissure on CT. ${ }^{31}$ Assessment with the Chartis ${ }^{\mathrm{TM}}$ system can improve TLVR prediction: $70.6 \%$ achieved TLVR among the patients who lacked collateral ventilation defined by the Chartis ${ }^{\mathrm{TM}}$ system. ${ }^{19}$ In our study, we chose patients with complete fissure and lacking collateral ventilation (as shown by the Chartis ${ }^{\mathrm{TM}}$ system) in consideration of cost-effectiveness, and 83.7\% (36/43) has achieved TLVR.

In about $15 \%$ of patients, the Chartis ${ }^{\mathrm{TM}}$ system does not clearly indicate whether collateral ventilation is present because of blockage of the catheter by secretions, apposition of the catheter against the airway wall, or anatomical factors. ${ }^{34,35}$ Indeed, in seven of our 43 patients (16.3\%), we could not come to a clear conclusion regarding collateral ventilation of the target lobe. These patients exhibited dynamic expiratory airway collapse or close bifurcation to place the catheter. In these patients, collateral ventilation of the adjacent lobe was tested. Since collateral ventilation in those adjacent lobes was not detected, the patients were deemed eligible for EBV insertion. In these seven patients, four achieved TLVR. Thus, in cases of inconclusive results regarding target lobe collateral ventilation, the results of the adjacent lobes could serve as a surrogate.

The prevalence of tuberculosis is higher in Korea than in Western countries. Together with smoking, it is a major risk factor for COPD in Asia. In our study, a relatively large proportion of patients $(23.3 \%)$ had a past history of tuberculosis. Patients with emphysema in tuberculosisprevalent countries such as Korea can have more heterogeneous phenotypes, and they exhibit hyperinflation at once, and their lung volume is reduced due to the presence of the inflammatory scar. Since the main effects of BLVR are due to the reduction of hyperinflation, its efficacy can be decreased by the presence of other pathogeneses such as fibrosis or previous inflammation associated with dyspnea. It is also possible that these pathogeneses elevate the risk of pneumothorax because lobes that bear scars can resist expansion. However, our data showed that the tuberculosis scar did not increase the achievement of TLVR or the development of pneumothorax. This may reflect the fact that in all nine patients with a tuberculosis scar, the scar affected lesser than $10 \%$ of the relevant lobes. This suggests that old inflammatory scars should not contraindicate BLVR if they are not widespread.

The number of adverse events in our study was modest compared to other studies. ${ }^{19,20,28}$ However, the pneumothorax rate was higher than that seen in previous trials $(23.3 \%$ vs $10.6 \%) .{ }^{29}$ This can be explained by several points. First, strict selection criteria were applied for patients who were expected to achieve TLVR. We excluded not only patients with incomplete fissure on CT, but also patients with collateral ventilation on Chartis ${ }^{\mathrm{TM}}$ system even though they had complete fissure. In previous studies, patients were selected without confirmation of collateral ventilation ${ }^{20,28,29}$ or complete fissure. ${ }^{19}$ Our strict strategy resulted in a higher rate of TLVR, followed by a higher rate of pneumothorax. In a recent review with lobar exclusion, $30 \%$ of a pneumothorax rate was also reported, which is consistent with our report. ${ }^{36}$ Second, the differences between the patient cohorts in terms of baseline characteristics such as the patients in our study were older and had a lower BMI and a poorer exercise capacity. Moreover, although our patients had a lower baseline $\mathrm{FEV}_{1}$ than those in the other cohorts, they also had less hyperinflation, as indicated by the RV. This together with the patient demographics suggests that the patients in our study could be particularly vulnerable to complications, such as pneumothorax. EBV is quite expensive compared to other medical cost in Korea and is not yet covered by the national insurance system. This may have caused patients to select BLVR as the last resort. This may reflect the fact that Asians tend to have smaller body sizes, including height or thoracic cage dimensions, than Westerners.

Our study has some limitations. First, the sample size was relatively small. This reflects the expense of BLVR with EBV in Korea, which caused many patients and their guardians to decide against the procedure during screening. It also reflects the fact that the physicians had to be very constrained in their selection of patients to maximize costeffectiveness. Second, many patients were lost to follow-up during the study period. This study was performed during the introduction of BLVR in Korea and, thus, the patients were referred from all around the country. Many of the patients who resided far from our center had difficulty in visiting regularly. Third, a significant number of patients were not assessed by 6MWD and SGRQ, although patients were followed up and were tested by spirometry and chest 
X-ray at 3 and 6 months. Spirometry, 6MWD, and SGRQ were performed on the same day. Because even spirometry was hard to perform for advanced emphysema patients, many patients refused to undertake 6MWD sequentially after spirometry. Furthermore, response to SGRQ was poor because of its lengthy questions in many patients.

\section{Conclusion}

The efficacy and safety of BLVR with EBV in Korea, an Asian country, were acceptable and consistent with the results of previous studies in Western countries. Thus, ethnicity and geographical area do not seem to affect the outcomes of BLVR as long as the clinical predictors of a response are present. However, the socioeconomic and medical environments can shape patient selection, which in turn could affect the results of procedure. Thus, the effort to reduce economic burden by reimbursement or cost-saving measures can expand the benefits of BLVR, especially in countries that have recently imported this treatment.

\section{Acknowledgments}

This study was supported by a grant from the National Strategic Coordinating Center for Clinical Research (HI10C2020) and the Korean Health Technology R\&D Project (HI14C3339), Ministry for Health and Welfare Affairs, Republic of Korea. We would like to thank Yee Hyung Kim (Kyung Hee University Hospital at Gangdong, Seoul, Korea) and Junghee Lee (Asan Medical Center, Seoul, Korea) for their support in the statistical analyses.

\section{Disclosure}

The author reports no conflicts of interest in this work.

\section{References}

1. Mathers CD, Loncar D. Projections of global mortality and burden of disease from 2002 to 2030. PLoS Med. 2006;3(11):e442.

2. Vestbo J, Hurd SS, Agustí AG, et al. Global strategy for the diagnosis, management, and prevention of chronic obstructive pulmonary disease: GOLD executive summary. Am J Respir Crit Care Med. 2013;187(4): 347-365.

3. Lee JH, Lee YK, Kim EK, et al. Responses to inhaled long-acting betaagonist and corticosteroid according to COPD subtype. Respir Med. 2009;104(4):542-549.

4. Cooper JD, Patterson GA, Sundaresan RS, et al. Results of 150 consecutive bilateral lung volume reduction procedures in patients with severe emphysema. J Thorac Cardiovasc Surg. 1996;112(5):1319-1329. discussion 1329-1330.

5. Cooper JD, Trulock EP, Triantafillou AN, et al. Bilateral pneumectomy (volume reduction) for chronic obstructive pulmonary disease. J Thorac Cardiovasc Surg. 1995;109(1):106-116. discussion 116-109.

6. Fishman A, Martinez F, Naunheim K, et al; National Emphysema Treatment Trial Research Group. A randomized trial comparing lungvolume-reduction surgery with medical therapy for severe emphysema. N Engl J Med. 2003;348(21):2059-2073.
7. Herth FJ, Gompelmann D, Ernst A, Eberhardt R. Endoscopic lung volume reduction. Respiration. 2010;79(1):5-13.

8. Salvi SS, Barnes PJ. Chronic obstructive pulmonary disease in nonsmokers. Lancet. 2009;374(9691):733-743.

9. Bhome AB, Brashier B. Profiles of chronic obstructive lung disease: characteristics of stable chronic obstructive lung disease in different parts of Asia. Curr Opin Pulm Med. 2014;20(2):165-172.

10. Eisner MD, Anthonisen N, Coultas D, et al; Committee on Nonsmoking COPD, Environmental and Occupational Health Assembly. An official American Thoracic Society public policy statement: novel risk factors and the global burden of chronic obstructive pulmonary disease. Am J Respir Crit Care Med. 2010;182(5):693-718.

11. Lee SW, Kim YS, Kim DS, Oh YM, Lee SD. The risk of obstructive lung disease by previous pulmonary tuberculosis in a country with intermediate burden of tuberculosis. J Korean Med Sci. 2011;26(2): 268-273.

12. Oh YM, Bhome AB, Boonsawat $\mathrm{W}$, et al. Characteristics of stable chronic obstructive pulmonary disease patients in the pulmonology clinics of seven Asian cities. Int J Chron Obstruct Pulmon Dis. 2013;8: 31-39.

13. Wu J, Dalal K. Tuberculosis in Asia and the pacific: the role of socioeconomic status and health system development. Int J Prev Med. 2012;3(1):8-16.

14. Menezes AM, Hallal PC, Perez-Padilla R, et al; Latin American Project for the Investigation of Obstructive Lung Disease (PLATINO) Team. Tuberculosis and airflow obstruction: evidence from the PLATINO study in Latin America. Eur Respir J. 2007;30(6): 1180-1185.

15. Elkington PT, Friedland JS. Matrix metalloproteinases in destructive pulmonary pathology. Thorax. 2006;61(3):259-266.

16. Park TS, Hong Y, Lee JS, et al. Efficacy of bronchoscopic lung volume reduction by endobronchial valves in patients with heterogeneous emphysema: report on the first Asian cases. J Korean Med Sci. 2014; 29(10):1404-1410.

17. Flandes Aldeyturriaga J. Bronchoscopic lung volume reduction: 7 lessons learned. Arch Bronconeumol. 2012;48(7):221-222.

18. Strange C, Herth FJ, Kovitz KL, et al. Design of the endobronchial Valve for Emphysema Palliation Trial (VENT): a non-surgical method of lung volume reduction. BMC Pulm Med. 2007;7:10.

19. Herth FJ, Eberhardt R, Gompelmann D, et al. Radiological and clinical outcomes of using Chartis to plan endobronchial valve treatment. Eur Respir J. 2013;41(2):302-308.

20. Herth FJ, Noppen M, Valipour A, et al; International VENT Study Group. Efficacy predictors of lung volume reduction with Zephyr valves in a European cohort. Eur Respir J. 2012;39(6):1334-1342.

21. Gompelmann D, Eberhardt R, Michaud G, Ernst A, Herth FJ. Predicting atelectasis by assessment of collateral ventilation prior to endobronchial lung volume reduction: a feasibility study. Respiration. 2010; 80(5):419-425.

22. Chae EJ, Kim N, Seo JB, et al. Prediction of postoperative lung function in patients undergoing lung resection: dual-energy perfusion computed tomography versus perfusion scintigraphy. Invest Radiol. 2013; 48(8):622-627.

23. Chae EJ, Seo JB, Jang YM, et al. Dual-energy CT for assessment of the severity of acute pulmonary embolism: pulmonary perfusion defect score compared with CT angiographic obstruction score and right ventricular/left ventricular diameter ratio. AJR Am J Roentgenol. 2010; 194(3):604-610.

24. Jones PW, Beeh KM, Chapman KR, Decramer M, Mahler DA, Wedzicha JA. Minimal clinically important differences in pharmacological trials. Am J Respir Crit Care Med. 2014;189(3):250-255.

25. Donohue JF. Minimal clinically important differences in COPD lung function. COPD. 2005;2(1):111-124.

26. Puhan MA, Chandra D, Mosenifar Z, et al; National Emphysema Treatment Trial (NETT) Research Group. The minimal important difference of exercise tests in severe COPD. Eur Respir J. 2011;37(4): 784-790. 
27. Jones PW. St George's respiratory questionnaire: MCID. COPD. 2005; 2(1):75-79.

28. Sciurba FC, Ernst A, Herth FJ, et al; VENT Study Research Group. A randomized study of endobronchial valves for advanced emphysema. N Engl J Med. 2010;363(13):1233-1244.

29. Gompelmann D, Herth FJ, Slebos DJ, et al. Pneumothorax following endobronchial valve therapy and its impact on clinical outcomes in severe emphysema. Respiration. 2014;87(6):485-491.

30. Venuta F, Anile M, Diso D, et al. Long-term follow-up after bronchoscopic lung volume reduction in patients with emphysema. Eur Respir J. 2012;39(5):1084-1089.

31. Valipour A, Herth FJ, Burghuber OC, et al; VENT Study Group. Target lobe volume reduction and COPD outcome measures after endobronchial valve therapy. Eur Respir J. 2014;43(2):387-396.
32. Shah PL, Herth FJ. Current status of bronchoscopic lung volume reduction with endobronchial valves. Thorax. 2014;69(3):280-286.

33. Reymond E, Jankowski A, Pison C, et al. Prediction of lobar collateral ventilation in 25 patients with severe emphysema by fissure analysis with CT. AJR Am J Roentgenol. 2013;201(4):W571-W575.

34. Gompelmann D, Eberhardt R, Herth FJ. Collateral ventilation. Respiration. 2013;85(6):515-520.

35. Shah PL, Herth FJ. Dynamic expiratory airway collapse and evaluation of collateral ventilation with Chartis. Thorax. 2014;69(3):290-291.

36. Valipour A, Slebos DJ, de Oliveira HG, et al. Expert statement: pneumothorax associated with endoscopic valve therapy for emphysemapotential mechanisms, treatment algorithm, and case examples. Respiration. 2014;87(6):513-521. 


\section{Supplementary materials}

Table SI Pulmonary function test, 6MWD, mMRC dyspnea scale, and SGRQ total score results 3 and 6 months after endobronchial valve therapy

\begin{tabular}{|c|c|c|c|}
\hline & Baseline & 3 months & 6 months \\
\hline Spirometry, subjects $n$ & 43 & 35 & 27 \\
\hline $\mathrm{FEV}_{1}, \mathrm{~L}$ & $0.68 \pm 0.26$ & $0.89 \pm 0.37 * * *$ & $0.92 \pm 0.40 * * *$ \\
\hline $\mathrm{FEV}_{1}, \%$ predicted & $24.5 \pm 10.7$ & $32.5 \pm 16.3 * * *$ & $33.8 \pm 17.9 * * *$ \\
\hline FVC, L & $2.50 \pm 0.75$ & $2.95 \pm 0.83 * *$ & $3.06 \pm 0.82 * *$ \\
\hline FVC, \%predicted & $63.8 \pm 17.3$ & $74.0 \pm 18.4 *$ & $78.7 \pm 15.9 * *$ \\
\hline TLC, L & $7.5 I \pm I .20$ & $6.91 \pm 1.31 *$ & $6.78 \pm 1.2 I^{*}$ \\
\hline Lung volume, subjects $n$ & 42 & 32 & 24 \\
\hline TLC, \%predicted & $126.7 \pm 18.8$ & $117.2 \pm 15.1 *$ & $116.0 \pm 14.7^{*}$ \\
\hline $\mathrm{RV}, \mathrm{L}$ & $4.98 \pm 1.15$ & $3.91 \pm 1.15^{* *}$ & $3.67 \pm 0.95 * * *$ \\
\hline RV, \%predicted & $208.7 \pm 47.9$ & $165.0 \pm 47.7 * * *$ & $155.9 \pm 42.6 * * *$ \\
\hline Diffusing capacity, subjects n & 43 & 31 & 23 \\
\hline $\mathrm{DL}_{\mathrm{co}}, \mathrm{mL} / \mathrm{min} / \mathrm{mmHg}$ & $6.1 \pm 2.5$ & $6.7 \pm 2.3^{*}$ & $6.6 \pm 2.3^{*}$ \\
\hline $\mathrm{DL}_{\mathrm{co}}$ \%predicted & $31.6 \pm 11.9$ & $34.9 \pm 10.7^{*}$ & $34.3 \pm 10.7 *$ \\
\hline Exercise capacity, subjects n & 40 & 31 & 21 \\
\hline 6MWD, m & $233.5 \pm 114.8$ & $283.7 \pm 121.6^{* *}$ & $299.6 \pm 87.5^{*}$ \\
\hline Dyspnea scale, subjects $n$ & 43 & 35 & 27 \\
\hline mMRC dyspnea scale & $3.7 \pm 0.6$ & $2.5 \pm 1.2 * * *$ & $2.4 \pm 1.2 * * *$ \\
\hline Quality of life, subjects n & 39 & 27 & 20 \\
\hline SGRQ total score* & $65.59 \pm 13.07$ & $55.70 \pm 13.79 * *$ & $53.76 \pm 11.40 *$ \\
\hline
\end{tabular}

Notes: The data are presented as mean $\pm \mathrm{SD}$. $* P<0.05$, $* * P<0.01$, and $* * * P<0.001$ compared to baseline, as determined by using Wilcoxon signed rank test.

Abbreviations: $\mathrm{DL}_{\mathrm{co}}$, diffusing capacity for carbon monoxide; $\mathrm{FEV}_{1}$, forced expiratory volume in I second; FVC, forced vital capacity; mMRC, modified Medical Research Council; RV, residual volume; SGRQ, St George's Respiratory Questionnaire; TLC, total lung capacity; 6MWD, 6-minute walk distance; SD, standard deviation.

Table S2 Effect of tuberculosis scar on target lobe volume reduction and pneumothorax

\begin{tabular}{|c|c|c|c|}
\hline & \multicolumn{2}{|c|}{ Tuberculosis scar } & \multirow[t]{2}{*}{$P$-value ${ }^{a}$} \\
\hline & No $(n=34)$ & Yes $(n=9)$ & \\
\hline \multicolumn{4}{|c|}{ Target lobe volume reduction } \\
\hline No & $5(14.5 \%)$ & $2(22.2 \%)$ & 0.624 \\
\hline Yes & $29(85.3 \%)$ & 7 (77.8\%) & \\
\hline \multicolumn{4}{|c|}{ Pneumothorax } \\
\hline No & $26(76.5 \%)$ & 7 (77.8\%) & 1.000 \\
\hline Yes & $8(23.5 \%)$ & $2(22.2 \%)$ & \\
\hline
\end{tabular}

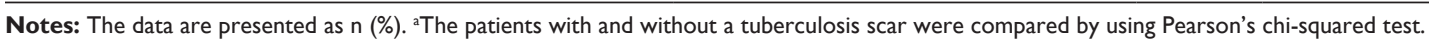

\section{Publish your work in this journal}

The International Journal of COPD is an international, peer-reviewed journal of therapeutics and pharmacology focusing on concise rapid reporting of clinical studies and reviews in COPD. Special focus is given to the pathophysiological processes underlying the disease, intervention programs, patient focused education, and self management protocols.

\section{Dovepress}

This journal is indexed on PubMed Central, MedLine and CAS. The manuscript management system is completely online and includes a very quick and fair peer-review system, which is all easy to use. Visit $\mathrm{http}: / / \mathrm{www}$.dovepress.com/testimonials.php to read real quotes from published authors. 